\title{
Resilience in a prehospital setting - a new focus for future research?
}

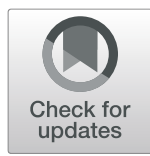

Elisabeth Jeppesen ${ }^{1,2^{*}}$ (D) and Siri Wiig ${ }^{2}$

\begin{abstract}
Background: Handling and initiating of treatment in a prehospital setting are complex processes that involve many treatment options and include several parts of the chain of survival. Capacity to adapt to unexpected changes in the patients' conditions or in the surroundings is a prerequisite for patient safety. Outside the healthcare sector, safety science is moving from an approach focused on the analysis and management of error (Safety I) to instead understanding the inherent properties of safety systems (Safety II). In healthcare the attention to why service providers are able to succeed under challenging conditions remains sparse. The aim of this commentary is to give a better understanding of how the concept and inclusion of resilience can inspire a new approach for future research in prehospital settings. So far, most resilience studies have been conducted in emergency departments while the role of contextual factors and adaptations in a prehospital setting has remained unexplored.

Main body: In contrast to traditional research on healthcare quality and safety, which tends to focus on failures, resilience research is interested in examining the overwhelming majority of healthcare processes with successful outcomes, to determine how high-quality patient care is generated. Resilience is conceptualized as a proactive ability to adjust to potentially harmful influences and challenges rather than to resist them. To better understand and promote resilience, there is a need to explore the underlying mechanisms of adaptation, trade-offs and improvisation that occur in the emergency chain. Attention to how people respond to disruptions, challenges and opportunities is vital. There are factors, recognized and unidentified, influencing adaptation, trade-offs and improvisation. Influencing factors at different levels could be of particular value to increase knowledge to better understand resilience in a practical perspective. As prehospital work conditions are highly unpredictable and diverse, learning through everyday work could be of great value if the experiences are transferred and integrated in training and simulation.

Conclusions: Empirical research is of crucial importance to build and support resilient systems and processes in a prehospital setting. We need a new framework and a new approach to how research on this topic is conducted and to support resilient performance. This should involve identifying factors that promote resilience, both on individual-, team- and system- levels.
\end{abstract}

Keywords: Prehospital, Emergency, Resilience, Adaptive capacity, Framework

\footnotetext{
* Correspondence: elisabeth.jeppesen@norskluftambulanse.no

${ }^{1}$ Department of Research and Development, Norwegian Air Ambulance

Foundation, NO-0103 Oslo, Norway

${ }^{2}$ SHARE Center for Resilience in Healthcare, Faculty of Health Science,

University of Stavanger, Stavanger, Norway
}

(c) The Author(s). 2020 Open Access This article is licensed under a Creative Commons Attribution 4.0 International License, which permits use, sharing, adaptation, distribution and reproduction in any medium or format, as long as you give appropriate credit to the original author(s) and the source, provide a link to the Creative Commons licence, and indicate if changes were made. The images or other third party material in this article are included in the article's Creative Commons licence, unless indicated otherwise in a credit line to the material. If material is not included in the article's Creative Commons licence and your intended use is not permitted by statutory regulation or exceeds the permitted use, you will need to obtain permission directly from the copyright holder. To view a copy of this licence, visit http://creativecommons.org/licenses/by/4.0/ The Creative Commons Public Domain Dedication waiver (http://creativecommons.org/publicdomain/zero/1.0/) applies to the data made available in this article, unless otherwise stated in a credit line to the data. 


\section{Background}

Capacity to adapt to unexpected changes, whether these changes are in the patients' conditions or in the environment, is a prerequisite for patient safety in a prehospital setting. Initial treatment require complex means, involve many treatment options and include several parts of the chain of survival [1], including first responder, dispatch, ambulance, advanced emergency medical treatment, triage and Emergency Departments (EDs).

Care is mostly delivered to low acuity patients, but with nonetheless complex conditions, and care is delivered to high-acuity patients with unstable vital signs in a fast-paced setting under unpredictable conditions [2]. Moreover, decisions must be made under great uncertainty. In addition, patient numbers and treatment needs, may vary considerably from situation to situation, while resources including staff, facilities and equipment often are limited. Dealing with both ordinary and extreme events, from single individuals to very complex major incidents with multiple casualties, requires adaptive capacity, flexibility, and coordination among different groups of professionals across the rescue services. Under such circumstances, human performance can be affected by individual human factors (e.g. disruptions, fatigue, and stress levels) and several environmental stressors (e.g. exposure to accidents, threatening patient behaviour) [3]. This highly dynamic work environments makes working in the prehospital environment particularly vulnerable for serious patient harm [4]. In general, the extent of medical errors and preventable harms increase under advancing complexity of care. This represents a major challenge for healthcare providers, policy makers and political leaders [5]. Outside the healthcare sector, safety science is moving from an approach focused on the analysis and management of error (Safety I) to instead understanding the inherent properties of safety systems (Safety II). In healthcare the attention to why service providers are able to succeed under challenging conditions remains sparse [6]. Due to the lack of research helping us to understand what factors may influence patient safety in a prehospital setting, the aim of this commentary is to give a better understanding of how the concept and inclusion of resilience can inspire a new approach for future research in prehospital settings. So far, most studies with a resilience perspective have been conducted in Eds [7, 8], however, generalizable models and methods for measuring resilience in EDs still remains a significant challenge, while the role of contextual factors in a prehospital setting are unexplored. We therefore need sufficient framework to be able to theorize and apply these concepts in a prehospital setting at individual, group and system levels.

\section{Main text}

\section{Patient safety and resilience}

There is broad agreement that a well-functioning trauma and emergency system, with a seamless treatment chain from scene to completed treatment, is essential for optimal patient outcome. However, there is a lack of studies investigating which elements contribute to increased quality and patient safety and why this treatment chain usually works well. A systematic review of studies evaluating the effects, reliability, validity and feasibility of interventions improving patient safety in emergency care identified a lack of evidence on effective safety governance strategies, particularly in the field of prehospital emergency care [9]. Simulation-based training and incident reporting systems with a focus on reducing the fear of reporting, reporting burden, and structural and systematic feedback, are promising interventions to improve the governance of patient safety in emergency care [9]. Articles discussing resilient health care in Eds recognized that to operate effectively and create value, EDs must be flexible, having the ability to rapidly adapt to the highly variable needs of patient [10]. Safety II and the resilience research is interested in examining the overwhelming majority of healthcare processes with successful outcomes to determine how high quality patient care is generated in everyday clinical practice [11]. Resilience in healthcare is conceptualized as a proactive ability to adjust to potentially harmful influences and challenges rather than to resist them, resulting in higher quality of care [12]. It's a term that can be understood in a variety of ways, both at the individual, team and system level. Our understanding of the resilience term as a multi-level phenomenon, considers adaptive capacity to changes as a foundation for high quality care [12]. In this conceptualization resilience is defined as: the capacity to adapt to challenges and changes at different system levels, to maintain high quality care, involving flexibility, adjustments, improvisation, adaptation, and variability [12]. Current research on patient safety and resilience lacks theoretical integration of the multiple levels of the healthcare systems, from individuals and teams (micro), to organisations (meso), to regulatory bodies and policy level actors (macro) [8]. Working with severely ill or injured patients in the emergency chain demands both clinical skills and leadership at a micro level, coordination, adaptability and preparedness across tactical, operational and strategic levels at a meso level $[13,14]$, and development and compliance to a set of functional procedures and regulation from the regulatory bodies at the macro level [15].

\section{Capacity to adapt}

To better understand and promote resilience, there is a need to explore the underlying mechanisms of adaptation, trade-offs and improvisation that occur in the emergency chain by exploring how people respond to 
disruptions, challenges and opportunities. There are factors, recognized at a personal level (self-efficacy, coping strategies and situation awareness) [16] and unidentified factors at system levels, influencing adaptation, tradeoffs and improvisation. Identifying influencing factors for adaptation at different levels is of great importance for being able to conduct research and explore resilience in a practical perspective. Often healthcare performers are unable to follow procedures, checklists and standards in all situations. In some cases, adaptations can be necessary for safe service provision. Checklists can contribute to relieve stress and improve teamwork processes and often, in stressful situations, professionals sink to the level of their training and to automized procedures [17]. The professionals working in the field know that although protocols and guidelines have their place, work is only possible by continually adjusting what you do, which sometimes means improvising and working outside the "protocols". This variability in performance is necessary to accommodate patients' needs and unpredictable situations.

Although satisfactory individual technical skills, in combination with standardization and implementation of evidence-based guidelines, are prerequisite for developing multitasking skills, it is often not not enough to be prepared for challenging situations and better adaptive capacity. Given that the prehospital work conditions are so unpredictable and differs in scope and frequency, learning through everyday work is fundamental but not enough [18]. In a resilience perspective, learning through systematic training and simulation focusing on what works well is an under used learning source with a potential to significantly improve performance $[19,20]$. Therefore, simulation can be an important tool for identifying factors that have an impact on adaptive capacity. However, apart from a small number of studies within certain clinical areas, healthcare research conducted from a resilience perspective in a prehospital setting is still in its infancy [7].

\section{Conclusions}

Empirical research is of crucial importance to understand, build and support resilient systems and processes, including exploring and developing interventions to improve capacity for adaptive change in a prehospital setting. There is a need for new approaches and a theoretical framework to inspire future research and support resilient performance. This should seek to identify enablers of resilience, both on individual, teams and system levels. These factors are prerequisites for developing competence, exploring and understanding of work practices, for developing proactive indicators, interventions and for a deeper understanding of the complexity and developing appropriate regulations.

\section{Acknowledgements}

Not applicable.

\section{Authors' contributions}

EJ and SW both contributed in writing the manuscript and have read and approved the final manuscript.

\section{Authors' information}

EJ is an associate professor at the University of Stavanger (UIS), in the PreHospital Critical Care master program (PHCC), Faculty of Health Sciences, UiS. $\mathrm{EJ}$ is part of SHARE-Centre for Resilience in Healthcare, at the Faculty of Health Sciences, UiS. She also works as a senior researcher at the Norwegian Air Ambulance Foundation (NAAF).

SW is full professor of quality and safety in healthcare systems and center director at SHARE-Centre for Resilience in Healthcare at the Faculty of Health Sciences, University of Stavanger, Norway.

\section{Funding}

The authors received no external funding.

Availability of data and materials

Not applicable.

Ethics approval and consent to participate

Not applicable.

\section{Consent for publication}

Not applicable.

\section{Competing interests}

The authors declare that they have no competing interests or disclosures.

Received: 11 September 2020 Accepted: 15 October 2020

Published online: 21 October 2020

\section{References}

1. Nolan J, Soar J, Eikeland H. The chain of survival. Resuscitation. 2006;71(3): 270-1.

2. Patterson PD, Arnold RM, Abebe K, Lave JR, Krackhardt D, Carr M, et al. Variation in emergency medical technician partner familiarity. Health Serv Res. 2011:46(4):1319-31.

3. Reid $B O$, Haugland $H$, Abrahamsen $H B$, Bjørnsen LP, Uleberg $O$, Krüger AJ. Prehospital Stressors: A Cross-sectional Study of Norwegian HelicopterEmergency Medical Physicians. Air Med J. 2020;39(5):383-8. https:// doi.org/10.1016/j.amj.2020.05.016. Epub 2020 Jun 24. PMID: 33012477.

4. Nemeth CP, Nunnally $M, O^{\prime} C o n n o r ~ M F$, et al. Regularly irregular: how groups reconcile cross-cutting agendas and demand in healthcare. Cogn Tech Work. 2007;9:139-48. https://doi.org/10.1007/s10111-006-0058-4.

5. Bates DW, Singh $\mathrm{H}$. Two decades since to err is human: an assessment of Progress and emerging priorities in patient safety. Health Aff (Millwood). 2018:37(11):1736-43.

6. Hagiwara MA, Magnusson C, Herlitz J, Seffel E, Axelsson C, Munters M, et al. Adverse events in prehospital emergency care: a trigger tool study. BMC Emerg Med. 2019;19(1):14.

7. Iflaifel M, Lim RH, Ryan K, Crowley C. Resilient health care: a systematic review of conceptualisations, study methods and factors that develop resilience. BMC Health Serv Res. 2020;20(1):324.

8. Berg SH, Akerjordet K, Ekstedt M, Aase K. Methodological strategies in resilient health care studies: an integrative review. Saf Sci. 2018;110:300-12.

9. Hesselink G, Berben S, Beune T, Schoonhoven L. Improving the governance of patient safety in emergency care: a systematic review of interventions. BMJ Open. 2016;6(1):e009837.

10. Back J, Ross AJ, Duncan MD, Jaye P, Henderson K, Anderson JE. Emergency department escalation in theory and practice: a mixed-methods study using a model of organizational resilience. Ann Emerg Med. 2017;70(5):659-71.

11. Braithwaite J, Wears RL, Hollnagel E. Resilient health care: turning patient safety on its head. Int J Qual Health Care. 2015;27(5):418-20.

12. Wiig S, Aase K, Billett S, Canfield C, Roise O, Nja O, et al. Defining the boundaries and operational concepts of resilience in the resilience in healthcare research program. BMC Health Serv Res. 2020;20(1):330. 
13. Sollid SJ, Rimstad R, Rehn M, Nakstad AR, Tomlinson AE, Strand T, et al. Oslo government district bombing and Utoya island shooting July 22, 2011: the immediate prehospital emergency medical service response. Scand J Trauma Resusc Emerg Med. 2012;20:3.

14. Rimstad R, Sollid SJ. A retrospective observational study of medical incident command and decision-making in the 2011 Oslo bombing. Int J Emerg Med. 2015;8:4

15. Oyri SF, Braut GS, Macrae C, Wiig S. Exploring links between resilience and the macro-level development of healthcare regulation- a Norwegian case study. BMC Health Serv Res. 2020;20(1):762.

16. Mao X, Loke AY, Hu X. Developing a tool for measuring the disaster resilience of healthcare rescuers: a modified Delphi study. Scand J Trauma Resusc Emerg Med. 2020;28(1):4.

17. Sollid SJM, Kamarainen A. The checklist, your friend or foe? Acta Anaesthesiol Scand. 2020;64(1):4-5.

18. Billett S. Learning through health care work: premises, contributions and practices. Med Educ. 2016;50(1):124-31.

19. Dieckmann P, Patterson M, Lahlou S, Mesman J, Nystrom P, Krage R. Variation and adaptation: learning from success in patient safety-oriented simulation training. Adv Simul (Lond). 2017;2:21.

20. Sollid SJM, Dieckman P, Aase K, Soreide E, Ringsted C, Ostergaard D. Five topics health care simulation can address to improve patient safety: results from a consensus process. J Patient Saf. 2019;15(2):111-20.

\section{Publisher's Note}

Springer Nature remains neutral with regard to jurisdictional claims in published maps and institutional affiliations.

Ready to submit your research? Choose BMC and benefit from:

- fast, convenient online submission

- thorough peer review by experienced researchers in your field

- rapid publication on acceptance

- support for research data, including large and complex data types

- gold Open Access which fosters wider collaboration and increased citations

- maximum visibility for your research: over $100 \mathrm{M}$ website views per year

At BMC, research is always in progress.

Learn more biomedcentral.com/submissions 